\title{
Osmotic and cytotoxic study of vitrification of immature bovine oocytes
}

\author{
A. Arav, D. Shehu and M. Mattioli \\ Istituto di Fisiologia Veterinaria, Universita' di Bologna Via Tolara di Sopra 50, 40064 Ozzano \\ Emilia, Bologna, Italy
}

\begin{abstract}
Four experiments were conducted to determine the composition of a solution suitable for vitrification of immature bovine oocytes. The osmotic and cytotoxic effect of different concentrations $\left(0,0.25,0.5\right.$ and $\left.1 \mathrm{~mol} \mathrm{I}^{-1}\right)$ of nonpermeating solutes (sucrose versus trehalose) were examined. In addition, the effect of permeating cryoprotectants such as glycerol, dimethyl sulfoxide, and propylene glycol $(40 \% \mathrm{w} / \mathrm{v})$ on the viability of oocytes was studied to determine the optimal time of exposure and the most suitable cryoprotectant. Exposure of bovine oocytes to trehalose was less harmful than exposure to sucrose $(P<0.01)$, and high normospermic fertilization $(70 \%)$ was achieved after exposure to 0.25 mol trehalose $1^{-1}$. Propylene glycol was chosen as the cryoprotectant for the vitrification of immature bovine oocytes because of its fast permeating rate and its low cytotoxic effect. The composition of this solution ( $40 \%$ propylene glycol and 0.25 mol trehalose $1^{-1}$ in PBS containing $4 \% \mathrm{w} / \mathrm{v}$ $\mathrm{BSA})$ appeared to be suitable for vitrification, as the fertilization rate of the vitrified oocytes was $37 \%$ (36 of 97 ).
\end{abstract}

\section{Introduction}

There is increasing interest in the development of gamete banks for embryo production by in vitro maturation (IVM) and in vitro fertilization (IVF). Effective cryopreservation of oocytes would greatly enhance their availability at every time and from low cost sources such as abattoir animals or from high genetic value animals (Pieterse et al., 1991).

Cryopreservation of oocytes and embryos has been attempted by vitrification (Rall and Fahy, 1985; Nakagata, 1989). Vitrification is the solidification of a liquid by an extreme increase in viscosity during very rapid cooling (Fahy et al., 1984). The solid, called glass, has the molecular and ionic distribution of the liquid state, and thus avoids the potentially detrimental effects of extracellular and intracellular crystallization. In addition, the oocytes are exposed to a range of temperatures from 15 to $0^{\circ} \mathrm{C}$, to which they are particularly sensitive (Heyman et al., 1986; Parks and Ruffing, 1992), for short periods only, as high cooling rates are used in this technique.

Successful vitrification has been reported for mouse (Rall, 1987), rabbit (Smorag et al., 1989), rat (Kono et al., 1988), pig (Rubinsky et al., 1992), ovine (Schiewe et al., 1990) and bovine (Massip et al., 1986) embryos and for mouse (Nakagata, 1989) and pig (Arav et al., 1990) oocytes. Vitrification requires the presence of a high concentration of cryoprotectant. It is therefore important to minimize the damage to cells by the osmotic stress or chemical toxicity caused by multimolar concentrations of the cryoprotectant used, which strictly depends on the kind of cell used. No ideal cryoprotectant that meets the requirements of all different species and developmental embryonic stages has been found; vitrification studies should therefore be preceded by osmotic and cytotoxic studies.

Received 12 October 1992.
Bovine oocytes have been cryopreserved either at the germinal vesicle or at the metaphase II stage. Lim et al. (1992) reported that bovine oocytes showed a greater fertilization ability when they were frozen at the metaphase II stage rather than at the germinal vesicle stage. However, many studies on mature (metaphase II) bovine and mouse oocytes have shown that specific structures such as the meiotic spindles are very sensitive to exposure to cryoprotectant (Van der Elst et al., 1988; Shaw and Trounson, 1989; Richardson and Parks, 1992) or to low temperatures (Magistrini and Szollosi, 1980; Pickering and Johnson, 1987) and undergo tubulin depolymerization. Immature bovine oocytes were therefore studied. We examined the osmotic behaviour of immature bovine oocytes exposed to high concentrations of different cryoprotectants and investigated their cytotoxic effects, to establish an optimal combination of cryoprotectants that permits successful vitrification.

\section{Materials and Methods}

\section{Source of oocytes}

Ovaries from cows and heifers were collected at a local abattoir immediately after slaughter and transported to the laboratory in PBS medium (Whittingham, 1971) at $20^{\circ} \mathrm{C}$. Immature oocytes at the germinal vesicle stage were recovered by aspiration through a 15-gauge needle from small follicles $(3-6 \mathrm{~mm}$ diameter). Only the oocytes enclosed in compact multilayer cumulus cells and with evenly granulated cytoplasm were used.

\section{Osmotic response to nonpermeating cryoprotectants}

Denuded oocytes were obtained by incubation at $20-22^{\circ} \mathrm{C}$ for $1-1.5 \mathrm{~min}$ in PBS containing $1 \mathrm{mg}$ hyaluronidase $\mathrm{ml}^{-1}$ (Sigma Chemical Co., St Louis, MO) and transferring them back 
to fresh PBS medium. Complete removal of cumulus cells was achieved by repeatedly aspirating the oocytes through a small bore pipette. Denuded oocytes were used in osmotic studies because the presence of the foot processes between cumulus cells and the oocyte causes an irregularly shaped shrinkage of the oolemma. The oocytes were then exposed to PBS containing $0,0.25,0.5$ and $1 \mathrm{~mol}$ sucrose $\mathrm{I}^{-1}$ (Sigma) or trehalose (Sigma) at $22^{\circ} \mathrm{C}$ for $10 \mathrm{~min}$. A telecamera connected to a Leitz inverted microscope (Fluovert, Germany) was used to record the oocytes for the whole time of exposure. Each oocyte was monitored continuously. The volume of the oocytes was determined from the cross-sectional area and the assumption of sphericity as described by Jackowsky et al. (1980). Oocytes contracting in a nonsymmetrical manner were not used.

In vitro development of germinal vesicle oocytes after exposure to nonpermeating cryoprotectants

After exposure to PBS solution containing $0.25,0.5$ and $1 \mathrm{~mol}$ sucrose or trehalose $1^{-1}$ for $10 \mathrm{~min}$ at $22^{\circ} \mathrm{C}$, cumulus enclosed oocytes were matured and fertilized in vitro. The oocytes were placed in TCM-199 medium (pH 7.4; Gibco Laboratories, New York) supplemented with $5 \mu \mathrm{g} \mathrm{LH} \mathrm{ml}{ }^{-1}$ (NIH-S20) and $5 \mu \mathrm{g} \mathrm{FSH} \mathrm{ml}^{-1}$ (LER441-2) as well as granulosa cells at the concentration of $5 \times 10^{4}$ cells ml $^{-1}$, and incubated at $38^{\circ} \mathrm{C}$ under $5 \% \mathrm{CO}_{2}$ in air for $26 \mathrm{~h}$. The oocytes were then washed, denuded and placed in the fertilization medium (Brackett and Oliphant, 1975) supplemented with $1.9 \mathrm{mg}$ caffeine $\mathrm{ml}^{-1}$ (Sigma). Capacitated bull spermatozoa were prepared from frozen bull semen in straws by the method of Fukui et al. (1990). The oocytes were collected $16 \mathrm{~h}$ after exposure to spermatozoa and fixed in acetic acid:alcohol ( $1: 3 \mathrm{v}: \mathrm{v})$. Twentyfour hours later, the oocytes were stained with Lacmoid (Sigma) and observed under a phase contrast microscope. The viability of oocytes was evaluated by their ability to undergo normal in vitro fertilization after in vitro maturation. An oocyte was considered normospermic if two pronuclei and the second polar body were observed. Fertilized oocytes could be distinguished from activated (parthenogenetic) oocytes by the presence of the remnant tail of the spermatozoon. The criteria for distinguishing digyny from dispermy was the presence of the second polar body.

\section{Osmotic response to concentrated solutions of permeating cryoprotectants}

Cumulus-free oocytes were directly introduced to PBS containing $40 \% \mathrm{w} / \mathrm{v}$ glycerol ( $\mathrm{BDH}$, Poole), dimethyl sulfoxide (DMSO, BDH), propylene glycol (Fluka Chemie, AG, Buchs) or mixtures of them $(20: 20 \mathrm{w}: \mathrm{V})$ at $22^{\circ}$. Video recordings were taken of the oocytes for the whole equilibration time (i.e. during which the oocyte regains the isotonic volume as a consequence of cryoprotectant penetration inside the cell) in each of these solutions. Determination of volume was performed as described above.

In vitro development of immature oocytes exposed to permeating cryoprotectant

The deleterious effect of the permeating cryoprotectants was evaluated by exposing the cumulus-enclosed oocytes to PBS

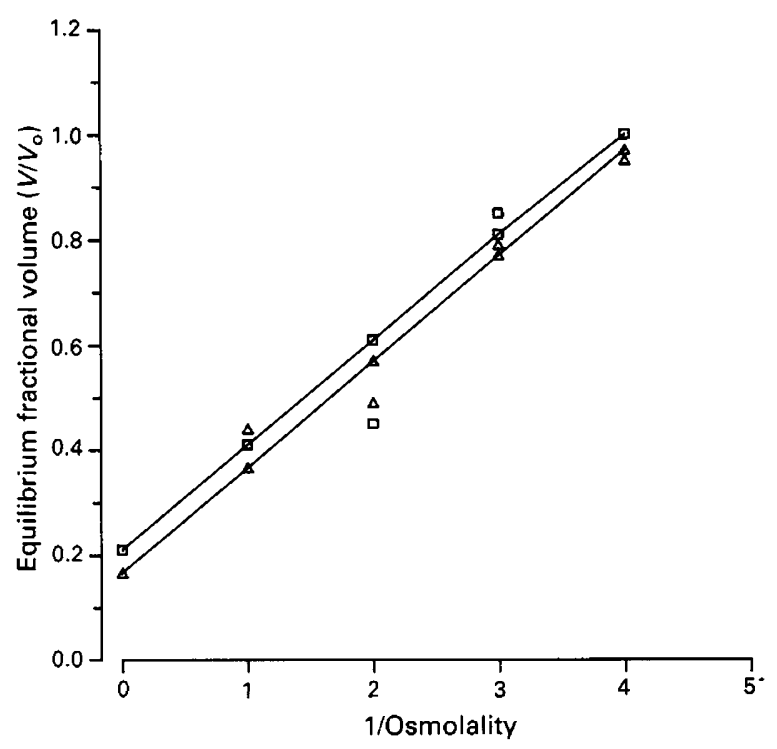

Fig. 1. Osmotic behaviour of oocytes when exposed to $(\Delta)$ sucrose and $(\square)$ trehalose solutions plotted as a Boyle Van't Hoff function. Mean values of the fractional volume in $0,0.25,0.5$ and $1 \mathrm{~mol}$ sucrose $1^{-1}(\triangle)$ and trehalose $1^{-1}(\square)$ in PBS are shown. Each point represents the mean of five determinations; SEM are too small to be shown.

solutions of propylene glycol, DMSO or glycerol $(40 \% \mathrm{w} / \mathrm{v})$ for the time required for equilibration found in Expt 3. The oocytes were then transferred to a culture dish containing $1 \mathrm{~mol}$ sucrose $1^{-1}$ in PBS to remove the cryoprotectant from the cells (Leibo, 1984). Fresh PBS was added drop by drop to reach a final sucrose concentration of $0.125 \mathrm{~mol} \mathrm{l}^{-1}$ within $10 \mathrm{~min}$ and the oocytes were then transferred to fresh PBS. The oocytes were matured and fertilized in vitro and their viability was assessed as described above.

\section{Vitrification of immature bovine oocytes}

On the basis of Expts 1, 2, 3 and 4, propylene glycol and trehalose were selected as the cryoprotectants for use in the vitrification solution.

Immature cumulus-enclosed oocytes were introduced at onestep into a vitrification solution containing propylene glycol $(40 \% \mathrm{w} / \mathrm{v})$ and trehalose $\left(0.25 \mathrm{~mol} \mathrm{l}^{-1}\right)$ in PBS supplemented with $4 \% \mathrm{w} / \mathrm{v}$ BSA until equilibrium was reached (10 $\mathrm{min}$ ). Some of the oocytes were immediately placed in $1 \mathrm{~mol}$ sucrose $1^{-1}$, diluted and cultured for IVM and IVF (solution control). Others were loaded in $5 \mu \mathrm{l}$ glass straws without being cooled and the contents were emptied into a culture dish containing $1 \mathrm{~mol}$ sucrose $1^{-1}$. The oocytes were then diluted and cultured as already described. The remaining oocytes were loaded in $5 \mu \mathrm{l}$ glass straws in a volume of $1 \mu \mathrm{l}$ and cooled in a directional solidification cryomicroscope (DCS Galcore, Mitzpe Aviv, IS) using a cooling and warming rate of $9600^{\circ} \mathrm{C} \mathrm{min}{ }^{-1}$ between predetermined temperatures $\left(20^{\circ} \mathrm{C}\right.$ to $\left.-140^{\circ} \mathrm{C}\right)$. The principle of directional solidification and the mathematical calculations of the cooling and warming rate were described by Rubinsky et al. (1991). A video camera was used in conjunction with the microscope to evaluate changes in morphology of the cells and the 
Table 1. Effect of different types and concentrations of nonpermeating cryoprotectants on in vitro fertilization of immature bovine oocytes

\begin{tabular}{|c|c|c|c|c|c|}
\hline \multirow[b]{2}{*}{ Treatment } & \multirow{2}{*}{$\begin{array}{l}\text { Total number } \\
\text { of oocytes }\end{array}$} & \multicolumn{2}{|c|}{$\begin{array}{c}\text { Number of oocytes } \\
\text { fertilized (\%) }\end{array}$} & \multirow{2}{*}{$\begin{array}{l}\text { Number of oocytes } \\
\text { unfertilized } \\
(\%)\end{array}$} & \multirow{2}{*}{$\begin{array}{c}\text { Number of oocytes } \\
\text { degenerated } \\
(\%)\end{array}$} \\
\hline & & Normospermic & Polyspermic & & \\
\hline Sucrose $\left(0.25 \mathrm{~mol} \mathrm{l}^{-1}\right)$ & $58^{\mathrm{a}}$ & $31(54)^{b}$ & $11(20)$ & $10(17)$ & $6(10)$ \\
\hline Sucrose $\left(0.5 \mathrm{~mol} \mathrm{l}^{-1}\right)$ & $69^{\circ}$ & $30(44)^{b}$ & $21(30)$ & $10(14)$ & $8(11)$ \\
\hline Sucrose $\left(1 \mathrm{~mol} \mathrm{l}^{-1}\right)$ & $60^{a}$ & $19(32)$ & $19(32)$ & $6(10)$ & $16(26)$ \\
\hline Trehalose $\left(0.25 \mathrm{~mol} \mathrm{l}^{-1}\right)$ & $60^{\mathrm{a}}$ & $42(70)^{c}$ & $9(15)$ & 7 (11) & $2(3)$ \\
\hline Trehalose $\left(0.5 \mathrm{~mol} \mathrm{l}^{-1}\right)$ & $66^{a}$ & $41(62)^{\mathrm{c}}$ & $17(26)$ & $2(3)$ & $6(9)$ \\
\hline Trehalose $\left(1 \mathrm{~mol} \mathrm{l}^{-1}\right)$ & $69^{\mathrm{a}}$ & $43(63)$ & $19(28)$ & $3(4)$ & $4(5)$ \\
\hline Control & $74^{\mathrm{a}}$ & $52(70)^{b}$ & $6(8)$ & $13(17)$ & $3(4)$ \\
\hline
\end{tabular}

'Results were pooled from three replicate experiments.

b.c Values with different superscripts within a column are significantly different $(P<0.01)$.

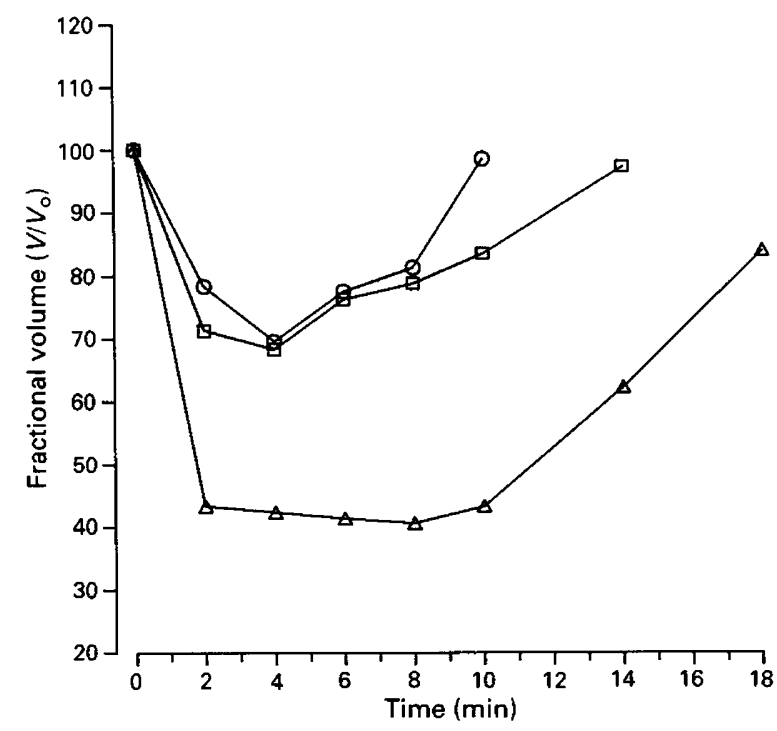

Fig. 2. Volumetric changes of oocytes during one-step exposure to concentrated solutions $(40 \% \mathrm{w} / \mathrm{v})$ of $(O)$ propylene glycol, ( $\square$ ) dimethyl sulfoxide and $(\triangle)$ glycerol. Each point represents the mean of five determinations; SEM are too small to be shown.

physical state of the solution as described by Rubinsky et al. (1991).

Immediately after warming, the oocytes were placed in PBS containing $1 \mathrm{~mol}$ sucrose $\mathrm{I}^{-1}$ to remove the cryoprotectant, diluted with fresh PBS within 10 min as already described and then transferred into fresh PBS. The viability of oocytes was assessed after IVM and IVF as described above.

\section{Statistical analysis}

Statistical comparisons were made using $\chi^{2}$ analysis. A probability of less than or equal to $0.01(P<0.01)$ was considered significant.

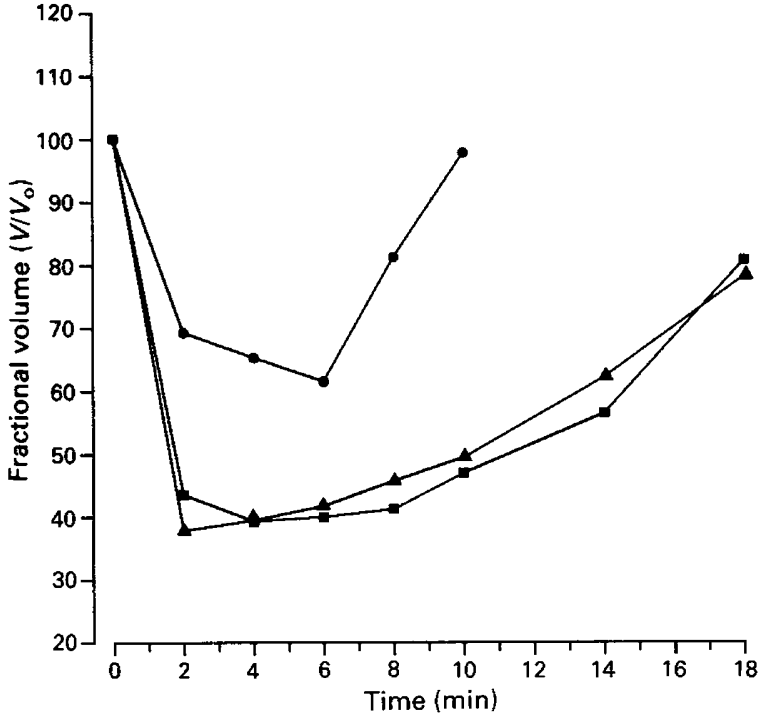

Fig. 3. Transient volume changes of oocytes exposed to mixtures $(20 \%$ $\mathrm{w} / \mathrm{v}+20 \% \mathrm{w} / \mathrm{v})$ of $(\mathbf{)})$ propylene glycol + dimethyl sulfoxide, ( $\boldsymbol{\square})$ propylene glycol + glycerol, and $(\boldsymbol{\Delta})$ dimethyl sulfoxide + glycerol. Each point represents the mean of five determinations; SEM are too small to be shown.

\section{Results}

\section{Effects of nonpermeating cryoprotectants}

The oocytes responded as a perfect osmometer over this range of osmolality (0.285-1.335) (Fig. 1). The regression analysis yielded the Boyle Van't Hoff function $F V_{\text {eq }}=0.166+$ $0.2^{*}\left(\mathrm{osmol}^{-1}\right), r=0.96(\mathrm{SD}=0.008)$ for the sucrose solutions and $F V_{\text {eq }}=0.212+0.285^{*}\left(\mathrm{osmol}^{-1}\right), r=0.98(\mathrm{SD}=0.006)$ for the trehalose solutions, where $F V_{\text {eq }}$ is the equilibrium fractional volume. No statistical differences were found between the sucrose and trehalose Van't Hoff plots $(P>0.01)$. The nonosmotic volume was similar to that of immature bovine oocytes found by Myers et al. (1987), but was much lower than that found by Ruffing et al. (1990). Fertilization rate is given as 
Table 2. Effect of high concentrations (40\%) of permeating cryoprotectants on in vitro fertilization rate of immature bovine oocytes

\begin{tabular}{lccccr}
\hline $\begin{array}{l}\text { Type of } \\
\text { cryoprotectant }\end{array}$ & $\begin{array}{c}\text { Total number } \\
\text { of oocytes }\end{array}$ & $\begin{array}{c}\text { Number of oocytes } \\
\text { fertilized (\%) }\end{array}$ & $\begin{array}{c}\text { Number of oocytes } \\
\text { unfertilized } \\
(\%)\end{array}$ & $\begin{array}{c}\text { Number of oocytes } \\
\text { degenerated } \\
(\%)\end{array}$ \\
\hline PG & $50^{\mathrm{a}}$ & $26(52)^{\mathrm{b}}$ & $4(8)$ & $8(16)$ & $12(24)$ \\
DMSO & $50^{\mathrm{a}}$ & $4(8)^{\mathrm{c}}$ & $2(4)$ & $2(4)$ & $42(84)$ \\
GLY & $50^{\mathrm{a}}$ & $6(12)^{\mathrm{c}}$ & $4(9)$ & $6(12)$ & $34(68)$ \\
Control & $54^{\mathrm{a}}$ & $30(55)^{\mathrm{b}}$ & $6(11)$ & $16(29)$ & $2(3)$ \\
\hline
\end{tabular}

'Results were pooled from two replicate experiments.

b. Values with different superscripts within a column are significantly different $(P<0.01)$.

PG: propylene glycol; DMSO: dimethyl sulfoxide; GLY: glycerol.

Table 3. Effect of vitrification on in vitro fertilization of immature bovine oocytes

\begin{tabular}{|c|c|c|c|c|c|}
\hline \multirow[b]{2}{*}{ Treatment } & \multirow{2}{*}{$\begin{array}{l}\text { Total number } \\
\text { of oocytes }\end{array}$} & \multicolumn{2}{|c|}{$\begin{array}{l}\text { Number of oocytes } \\
\text { fertilized (\%) }\end{array}$} & \multirow{2}{*}{$\begin{array}{l}\text { Number of oocytes } \\
\text { unfertilized } \\
(\%)\end{array}$} & \multirow{2}{*}{$\begin{array}{c}\text { Number of oocytes } \\
\text { degenerated } \\
(\%)\end{array}$} \\
\hline & & Normospermic & Polyspermic & & \\
\hline Vitrifiçation & $97^{\mathrm{a}}$ & $36(37)^{b}$ & $10(17)$ & $10(10)$ & $41(42)$ \\
\hline Solution effect & $49^{a}$ & $26(53)^{d}$ & $6(12)$ & $2(4)$ & $15(30)$ \\
\hline $\begin{array}{l}\text { Exposure to VS in } \\
\text { straws }\end{array}$ & $63^{\mathrm{a}}$ & $30(48)^{d}$ & $7(11)$ & $9(17)$ & $17(26)$ \\
\hline Control & $120^{a}$ & $80(69)^{c}$ & $13(10)$ & $13(10)$ & $14(11)$ \\
\hline
\end{tabular}

'Results were pooled from three replicate experiments.

b.c.dValues with different superscripts within a column are significantly different $(P<0.01)$.

VS: vitrification solution.

the ratio of the oocytes that showed normospermy to the total number of oocytes treated (Table 1). The normospermic fertilization rate of the oocytes after exposure to 0.25 and $0.5 \mathrm{~mol}$ sucrose $\mathrm{I}^{-1}$ was significantly different $(P<0.01)$ from 0.25 and $0.5 \mathrm{~mol}$ trehalose $\mathrm{I}^{-1}$, respectively $(54 \%$ versus $70 \%$ and $44 \%$ versus $62 \%$ ). The difference was much higher after exposure to $1 \mathrm{~mol}$ of sucrose and trehalose $1^{-1}$. Only $32 \%$ of oocytes were normally fertilized after exposure to $1 \mathrm{~mol}$ sucrose $\mathrm{I}^{-1}$ but $63 \%$ showed normospermy after exposure to $1 \mathrm{~mol}$ trehalose $\mathrm{I}^{-1}$. The incidence of polyspermy was therefore high after exposure to solutions of $0.5 \mathrm{~mol} \mathrm{l}^{-1}$ of both sugars; about $30 \%$ of polyspermy was found in the two groups.

\section{Effects of permeating cryoprotectants}

The oocytes exposed to propylene glycol or DMSO showed maximum shrinkage to $68 \%$ of the isotonic volume within $4 \mathrm{~min}$ (Fig. 2). During re-expansion, they reached a volume equal to the isotonic volume in $10 \mathrm{~min}$. The same behaviour was observed in the oocytes exposed to the mixture of PG plus DMSO (Fig. 3).

On the contrary, the equilibration time of immature bovine oocytes in glycerol or in its mixtures with PG or DMSO was about $90 \mathrm{~min}$ and the minimal volume reached in 2-8 min was lower than $50 \%$ of the isotonic volume (Figs 2 and 3). These results are very similar to the equilibration time reported by Myers et al. (1987) for bovine oocytes at the germinal vesicle stage in TL-Hepes plus $1 \mathrm{~mol}$ glycerol $1^{-1}$. The oocytes exposed to propylene glycol showed a fertilization rate not significantly different $(P>0.01)$ from that of the control group (Table 2). Only six of the 50 oocytes exposed to glycerol were fertilized; the viability of the oocytes after exposure to DMSO was very low ( $8 \%$ of them had two pronuclei). In addition, many of the oocytes of these two groups degenerated (34 out of 50 for the glycerol group and 42 out of 50 for the DMSO group). The number of activated oocytes did not exceed $1 \%$ in either group.

\section{Vitrification of immature bovine oocytes}

The results of examination by microscope of oocytes matured and fertilized in vitro after being vitrified in the vitrification solution (VS) containing $40 \% \mathrm{w} / \mathrm{v}$ propylene glycol and 0.25 mol trehalose $1^{-1}$ in PBS supplemented with $4 \%$ BSA are shown (Table 3). After vitrification, $54 \%$ (46 of 97) of the oocytes were fertilized and $37 \%$ showed normospermy. This value was significantly different from that of the control solution group in which 80 of $120(69 \%)$ fertilized normally. Exposure of oocytes to the vitrification solution caused a slight loss of viability and a decrease in fertilization ability. However, there was no significant difference between the fertilization rate 
of the oocytes exposed to the vitrification solution for $10 \mathrm{~min}$ (solution effect) or for the real time $(16 \mathrm{~min})$ needed for the vitrification procedure (exposure to VS in straws).

\section{Discussion}

The presence of cryoprotectant in the vitrification solution decreases the probability of intracellular crystallization which is considered to cause most damage when very rapid cooling takes place, but the high concentration of the cryoprotectant required is toxic and causes osmotic injury to the oocytes even without cooling.

Different methods have been used to reduce this 'solution effect': (i) short time of exposure to cryoprotectants (Fahy et al., 1984; Arav et al., 1988), (ii) use of low toxicity cryoprotectants (Rall, 1987) or mixtures of them (Massip et al., 1986), (iii) addition of nonpermeating cryoprotectants (Fahy et al., 1984), (iv) reduction of the cryoprotectant concentration (Rall, 1987), (v) exposure at low temperatures (Rall, 1987).

The use of nonpermeating cryoprotectants is very useful either because the shrinkage of the oocyte and consequently the amount of water inside the cell that may crystallize during rapid cooling and warming is lower (Rall, 1987) or because of the reduction of the amount of the cryoprotectant that penetrates the cell thus reducing the possible toxic effect (Szell and Shelton, 1987). In addition, the carbohydrates used as a nonpermeating cryoprotectant have a stabilizing effect on membranes (Crowe et al., 1983). In the study reported here trehalose was less harmful than sucrose. Determination of the Boyle Van't Hoff relationship for both sucrose and trehalose produced the same regression line, so it is possible that this beneficial effect could be a consequence of its interaction with the membrane (Crowe et al., 1983). In addition, higher survival rates were obtained after exposure to sucrose or trehalose solutions than to the solution reported by Heyman et al. (1986) in which immature bovine oocytes were already sensitive to $0.25 \mathrm{~mol}$ sucrose $1^{-1}$. The exposure to even $0.5 \mathrm{~mol}$ sucrose and trehalose $\mathrm{I}^{-1}$ and the consequent volume reduction of $50 \%$ did not affect the ability of immature bovine oocytes to mature and fertilize normally in vitro. An increase in the frequency of polyspermic fertilization was observed; volume changes induced by the cryoprotectant may alter the spatial relationship between cortical granules and the oolemma, thus impairing their exocytosis at fertilization and therefore the block to polyspermy.

Only $10 \mathrm{~min}$ of exposure are required for equilibration in propylene glycol and DMSO solutions or mixtures of them. The membrane is very permeable to both of them. The one-step exposure to these cryoprotectants is not likely to cause marked osmotic damage to the cell as the volume is reduced only up to $68 \%$ of the isotonic volume. Step-wise addition of the cryoprotectant therefore seems unnecessary.

The exposure to glycerol solution causes injury to the membrane that is probably attributable to the considerable shrinkage during the long period of equilibration. Titration of the glycerol solution seems a good approach to attain major viability after vitrification (data not shown). In addition mixtures of propylene glycol or DMSO with glycerol produced the same osmotic effect and are not suggested.
DMSO was the most harmful of the cryoprotectants used in this study, as few oocytes exposed to a $40 \% \mathrm{w} / \mathrm{v}$ DMSO underwent IVF after IVM. It probably has a toxic effect on the oocytes. In addition, vitrification solutions based on $40 \%$ w/v DMSO or glycerol were devitrified upon warming (data not shown). By contrast, the vitrification solution based on propylene glycol $(40 \% \mathrm{w} / \mathrm{v})$ did not show any type of crystallization that could be detected by the cryomicroscope. The results of the vitrification provide evidence that propylene glycol can be used successfully. Indeed, the IVF rate of the oocytes vitrified in a solution containing $40 \% \mathrm{w} / \mathrm{v}$ propylene glycol was $37 \%$ and is not different from the results obtained by Schellander et al. (1988) using a slow freezing protocol.

Rall et al. (1989) successfully increased the viability of vitrified mouse embryos by reducing the concentration of the cryoprotectant ( $90 \%$ of vitrification solution). However, concentrated solutions of permeating cryoprotectant are required for successful cryopreservation of oocytes when rapid cooling and warming rates are used. In earlier reports on immature pig oocytes, we showed that when lower concentrations of cryoprotectant are used, despite apparent vitrification, membrane destruction was unavoidable (Rubinsky et al., 1991). In this study, evaluation of the oocytes by microscope after vitrification did not reveal any membrane damage. Moreover, in the study reported here, no increased incidence of polyspermy was seen in the vitrified oocytes. Exposure of the oocytes to the vitrification solution caused a loss of viability probably because of the initial osmotic shock. Propylene glycol does not seem to have a toxic effect as prolonged exposure to vitrification solution did not cause any further loss of viability. The decrease in fertilization rate was probably due to zona hardening brought about by exposure to cryoprotectants but this needs to be investigated further. No increase in parthenogenetic activation of the oocytes was observed as a result of exposure to cryoprotectants. Rubinsky et al. (1992) reported that antifreeze glycoproteins could protect cell membranes from damage caused by low temperatures. The viability of immature pig oocytes and of pig and mouse embryos was increased when antifreeze glycoproteins were added to the vitrification solution at a concentration of $40 \mathrm{mg} \mathrm{ml}^{-1}$.

We suggest that the use of this glycoprotein together with the vitrification solution proposed here could be a great challenge for reaching a successful cryopreservation of immature bovine oocytes.

This work was supported by the National Research Council of Italy, Special Project RAISA, sub-project No. 3, Paper No. 738

\section{References}

Arav A, Gianaroli L and Suriano P (1988) Titration of vitrification solution in mouse embryo cryopreservation Cryobiology 26567 (Abstract)

Arav A, Bacci ML and Rubinsky B (1990) Vitrification of immature pig oocytes. In Proceedings of the 11th International Pig Veterinary Society Congress, Lausanne, p 479 (Abstract). Ed. H Keller. Fritz Weibel AG, Thun

Brackett BG and Oliphant G (1975) Capacitation of rabbit spermatozoa in vitro Biology of Reproduction 12 260-274

Crowe J, Crowe L and Mouradian R (1983) Stabilization of biological membranes at low water activities Cryobiology 20 346-356 
Fahy GM, MacFarlane DR, Angell CA and Meryman HT (1984) Vitrification as an approach to cryopreservation Cryobiology 21 407-426

Fukui Y, Sonoyama T, Mochizuki H and Ono H (1990) Effects of heparin dosage and sperm capacitation time on in vitro fertilization and cleavage of bovine oocytes matured in vitro Theriogenology 34 579-591

Heyman Y, Smorag Z, Katska L and Vincent C (1986) Influence of carbohydrates, cooling and rapid freezing on viability of bovine non-matured oocytes or I-cell fertilizing eggs Cryo-Letters 7 170-183

Jackowski SC, Leibo SP and Mazur P (1980) Glycerol permeabilities of fertilized and unfertilized mouse ova Journal of Experimental Zoology 212 329-341

Kono T, Suzuki O and Tsunoda Y (1988) Cryopreservation of rat blastocysts by vitrification Cryobiology 25 170-173

Leibo SP (1984) A one-step method for direct nonsurgical transfer of frozen-thawed bovine embryos Theriogenology 21 767-790

Lim JM, Fukui $Y$ and Ono H (1992) Developmental competence of bovine oocytes frozen at various maturation stages followed by in vitro maturation and fertilization Theriogenology 37 351-362

Magistrini M and Szollosi D (1980) Effects of cold and isopropyl- $N$ phenylcarbamate on the second meiotic spindle of mouse oocytes Journal of Cell Biology 22 669-707

Massip A, Van der Zwalmen P and Ectors F (1986) Pregnancies following transfer of cattle embryos preserved by vitrification Cryo-Letters 7 270-273

Myers SP, Lin T, Pitt RE and Steponkus PL (1987) Cryobehaviour of immature bovine oocytes Cryo-Letters 8 260-275

Nakagata N (1989) High survival rate of unfertilized mouse oocytes after vitrification Journal of Reproduction and Fertility 87 479-483

Parks JE and Ruffing NA (1992) Factors affecting low temperature survival of mammalian oocytes Theriogenology 37 59-73

Pickering SJ and Johnson MH (1987) The influence of cooling on the organization of the meiotic spindle of the mouse oocyte Human Reproduction 2 207-216

Pieterse MC, Vos PLAM, Kruip ThAM, Wurth YA, van Beneden ThH, Willemse AH and Taverne MAM (1991) Transvaginal ultrasound guided follicular aspiration of bovine oocytes Theriogenology 35 19-24
Rall WF (1987) Factors affecting the survival of mouse embryos cryopreserved by vitrification Cryobiology 24 387-402

Rall WF and Fahy GM (1985) Ice free cryopreservation of mouse embryos at $-196^{\circ} \mathrm{C}$ by vitrification Nature $313573-575$

Rall WF, Wood MJ, Kirby C and Whittingham DG (1989) Development of mouse embryos cryopreserved by vitrification Journal of Reproduction and Fertility 80 499-504

Richardson RR and Parks JE (1992) Effects of chilling on the meiotic spindle of bovine ova Theriogenology 37 284-287

Rubinsky B, Arav A and Devries AL (1991) Cryopreservation of oocytes using directional cooling and antifreeze glycoproteins Cryo-Letters 12 93-106

Rubinsky B, Arav A and Devries AL (1992) The cryoprotective effect of antifreeze glycopeptides from antarctic fishes Cryobiology 29 69-77

Ruffing NA, Parks JE, Pitt RE and Steponkus PL (1990) Effect of developmental stage on the osmotic properties of bovine oocytes Cryobiology 27675

Schellander K, Bracket BG, Fuhrer F and Schleger W (1988) In vitro fertilization of frozen thawed cattle oocyte. In Proceeding of 11th International Congress on Animal Reproduction and Artificial Insemination, Dublin pp 349-351

Schiewe MC, Rall WF, Stuart LD and Wildt DE (1990) In situ straw dilution of ovine embryos cryopreserved by conventional freezing or vitrification Theriogenology 33321 (Abstract)

Shaw JM and Trounson AO (1989) Parthenogenetic activation of unfertilized oocytes by exposure to 1,2-propanediol is influenced by temperature, oocytes age, and cumulus removal Gamete Research 24 269-279

Smorag Z, Gajda B, Wieczorek B and Jura J (1989) Stage dependent viability of vitrified rabbit embryos Theriogenology 31 1227-1231

Szell A and Shelton IN (1987) Osmotic and cryoprotective effect of glycerolsucrose solution on day-3 mouse embryos Journal of Reproduction and Fertility $80309-316$

Van der Elst J, Van der Abeel F, Jacobs R, Wisse E and Van Steirteghem A (1988) Effect of 1,2-propanediol and dimethysulphoxide on the meiotic spindle of the mouse oocyte Human Reproduction 3 960-967

Whittingham DG (1971) Survival of mouse embryos after freezing and thawing Nature 233 125-126 